\title{
The use of corpora in an interdisciplinary approach to localization
}

\author{
Parthena Charalampidou ${ }^{1}$ [0000-0002-5047-228X] \\ ${ }^{1}$ Aristotle University of Thessaloniki, University Campus, 54124, Greece \\ pcharefrl.auth.gr
}

\begin{abstract}
Translation Studies and more specifically, its subfield Descriptive Translation Studies (Holmes 1988/2000) is, according to many scholars (Gambier 2009; Nenopoulou 2007; Munday 2001/2008; Hermans 1999; Snell-Hornby et al. 1994 e.t.c), a highly interdisciplinary field of study. The aim of the present paper is to describe the role of polysemiotic corpora in the study of university website localization from a multidisciplinary perspective. More specifically, the paper gives an overview of an on-going postdoctoral research on the identity formation of Greek universities on the web, focusing on the methodology of corpora compilation and analysis with methodological tools and concepts from various fields, such as translation studies, social semiotics, cultural studies, critical discourse analysis and marketing. The objects of comparative analysis are Greek and French original and translated (into English) university websites as well as original British and American university website versions. Up to now, research findings have shown that polysemiotic corpora can be a valuable tool not only of quantitative but also of qualitative analysis of website localization both for scholars and translation professionals working with multimodal genres.
\end{abstract}

Keywords: polysemiotic corpora, university website localization, multimodal analysis and corpora.

\section{$1 \quad$ Introduction}

Several studies, that focus on websites and their communication and interaction with users, adopt approaches from the fields of cultural and marketing studies. These studies mostly aim at revealing the cultural differences that exist in the online marketing of companies and organizations (Simin, Tavangar and Pinna 2011; Salerno-O' Shea 2006; Dormann and Chisalita 2002; Leonardi 2002; Robbins and Stylianou 2002; SchmidIsler 2000; Marcus and Gould 2000; Sheppard and Scholtz 1999; Russo and Boor 1993; del Galdo 1990 e.t.c.). A lot of research has also been conducted with tools and methodologies from the fields of linguistics and more specifically, text linguistics and critical discourse analysis for the study of textual genres such as websites and textual functions in multimodal texts (Santini 2010, 2007, 2006; Bateman 2008; van Leeuwen 2008; Askehave and Nielsen 2004; Lemke 2002; Yli-Jokipii 2001; Fritz 1999; Storrer 1999; Wee 1999; Landow 1997; Martin 1997; Bohle 1990; Reiss 1971/2002 e.t.c.). As 
multimodal texts combine more than one semiotic system to create meaning and achieve their communicative goal, there is an urgent need for the adoption of methodological tools from the field of semiotics. This is obvious in various studies, which focus on the multimodality of genres, using semiotics-oriented methodological tools (Tomášková 2015, 2011; Jewitt 2009/2011; Ventola and Guijarro 2009; Baldry and Thibault 2006; O'Halloran 2004 e.t.c.). The application of theories and methodological tools from the above-mentioned fields could help us a) recognize the university website communicative function, b) study whether this function is retained or not in different language versions and c) highlight the parameters that define its retention or modification.

For the systematic and comparative analysis of our research material, we have created a mini corpus, comprising of both pictorial and verbal elements with the UAM Image Tool (O' Donnell 2008). These corpora consist of the homepages of Greek and French university websites, in original and universalized (Floros and Charalampidou 2020) versions, as well as the original versions of American and British websites. In the second case, English is used as an original language, so it is a good point of reference and comparison with versions that are localized in English. The main criterion for the analysis of the specific language versions was the familiarity of the researcher with the respective languages. Additionally, in most Greek and French university websites, the alternative version provided, in most cases, is English, a phenomenon with an increasing tendency in other countries as well (Callahan 2012).

\section{Research Questions}

University website localization is a challenge both for the translation scholar and the translation professional. It is also of great research interest due to the multimodal nature of the texts involved (hypertexts) as well as the cultural and social dimensions it can take. However, it has been rather unexplored, up to now, in the international literature. There is only limited literature on the interlingual study of university websites, which focuses mainly on content transfer and language policies (Apperson 2015, Tomášková 2015, Callahan 2012, 2006, Simin, Tavangar and Pinna 2011, Bernardini, Ferraresi,Gaspari 2010). Also, very few studies refer to Greek university websites (Callahan 2012, 2006). However, these are insufficient, as the first one is limited to the study of verbal choices in each website (Callahan 2012), and the second one examines solely the macrolevel. Also, given the fact that the second research was conducted fifteen years ago (Callahan 2006), it displays major differences from the current online image of Greek universities. Additionally, according to literature up to now, there is no systematic study focusing on the way Greek higher education institutions approach a foreign audience, and no attempts have been made to create multimodal corpora with Greek university website homepages. Taking into consideration the research gap that exists in the field our research has attempted to:

a) Map the translation practice in the genre of university websites in Greece and interrelate the localization choices, both on macro- and micro-level, with the 
cultural background of the receivers as well as with the new social and economic conditions on national and international level.

b) Define the way the identity of Greek universities is projected on the web and compare it with the identity of English- and French-speaking universities.

With these goals in mind the following steps have been taken:

- Compilation of a polysemiotic corpus with Greek, French and English university websites with the UAM Image Tool (O' Donnell 2008).

- Recording of content and hyperstructure localization techniques in Greek universalized versions.

- Recording of microtextual localization techniques in Greek universalized versions on verbal and optical level.

- Recording of microtextual localization techniques in French universalized versions on verbal and optical level.

- Comparison of Greek university websites with French and British/American ones on macro- and micro-level.

- Association of localization techniques on macro- and micro-level with cultural, social and economic factors.

\section{$3 \quad$ Methodology}

The preliminary study includes six Greek and six French university websites both in their original (French/Greek) and their universalized version as well as six British/ American university websites in their original version. The corpus was drawn from the THE World University Rankings for 2019 comprising of universities in a similar ranking. The systematic study and observation of the sum of websites in all four language versions (Greek, French, localized English and original English) required the compilation of a mini corpus (Zanettin 1994). The corpus belongs to the category of specialized corpora which include specialized texts of a specific type and are used for the study of a specific type of language (Hunston 2002: 14). According to Flowerdew (1993:232) corpora which are small in size are adequate when the study focuses on a specific domain. Additionally, specialized comparable corpora (multilingual and monolingual) are used, among others, to track functional translational equivalents ("units" that can be compared on the denotational, the connotational and the pragmatic level) (Tognino Bonelli 2002).

In the first part of the research we compiled a polysemiotic corpus using the UAM Image Tool (O' Donnell 2008), which is free software that allows the annotation of images, that is the introduction of verbal interpretative information (Habert 2005; Leech 2005). The term 'polysemiotic' is used here to denote corpora that do not include solely one semiotic system, namely language, image or sound but rather combine the annotation of images with the verbal elements that anchor the pictorial meaning. Next, images were annotated manually on different levels and sublevels. Methodological tools from the field of social semiotics (isotopies (Greimas 1966), anchorage (Barthes 2007), 
metafunctions (Kress and van Leeuwen 1996) constituted the basis for the annotation of the pictorial elements of university websites.

The notion of isotopy is a key term in social semiotics and has been suggested by Greimas (1966) who, since the late 1960s, has been a central figure in the Paris School of Semiotics. His theory of structural semantic isotopy can be applied both on lexical and non-lexical units allowing for the description of the coherence and homogeneity of meaning in a multimodal text, such as the website, by connecting figures different from one another. Through the detection of repetitive semes (parts of the meaning of a word) the isotopies in a text can be identified and, thus, content analysis is enhanced. Since the aim of our research on the macrolevel was to detect similarities and differences regarding content in university websites, the notion of isotopy was adopted.

The multisemiotic nature of the website genre also calls for the study of meaning creation through the synergy of image and text. Another concept that was drawn from the field of social semiotics was that of image-text relation. Acccording to Barthes (2007:50-59), the iconic message can be divided into a) literal and b) symbolic. This distinction actually refers to the separation of the denotational description of an image from the connotations that it bears. Taking for granted that every image is polysemous Barthes (2007: 46) suggests that through verbal messages the receiver of the message is directed to the selection of specific signifieds related to the image's signifiers and to the avoidance of others. The verbal message's function in relation to the visual one is called anchorage and elsewhere than in advertising its principal function may be ideological since the reader can be directed to a preselected concept (Barthes 2007, 48). In the light of these notions we were able look for the connoted verbo-pictorial messages within university websites and correlate them to their communicative function in each linguistic version.

The third semiotic-oriented tool which allowed for the comparative study of persuasive multimodal meaning making was the grammar of visual design that Kress and van Leeuwen (2006/1996) have suggested. More specifically, these authors (2006/1996) developed a method of social semiotic analysis of visual communication, based on Halliday's social semiotics, and suggested a descriptive framework of multimodality, based on three metafunctions, namely:

a) the representational metafunction, which describes what is represented in an image and includes either (i) conceptual processes, which can be attributive highlighting one represented participant of the two depicted or suggestive involving just one represented participant, or (ii) presentational processes that function as a narrative;

b) the interpersonal metafunction, which is the representation of relations between image and viewer and describes (i) mood, that is the participant's gaze that can constitute either an offer or a demand, (ii) perspective, which defines the power relations between image and viewer as well as the degree of the viewer's involvement, and (iii) social distance, which refers to the degree of familiarity between image and viewer.

c) the compositional metafunction, which refers to the codes that operate in the layout of an image to produce meaning and create textual coherence such as (i) salience, (ii) reading path, (iii) vectors, (iv) compositional axes, and (v) centers and margins.

For example, for the annotation of the interpersonal metafunction in images (Kress and van Leeuwen 1996) various sublevels were created such as: 
- the shooting angle on the horizontal and the vertical axis which defines power relations and social distance between the viewer and the represented participants on the image,

- the offer or demand of information, depending on a straight or oblique gaze of the represented participants

- the distance of the shot (close, medium, long) which defines the degree of contact between the viewer and the represented participants.

In the following figures the sublevels of the interpersonal metafunction are depicted:

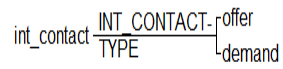

Fig. 1 Interpersonal function: Contact

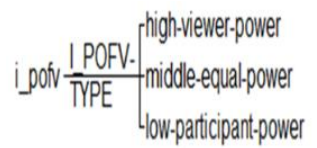

Fig. 3 Interpersonal function: Point of view-

vertical axis

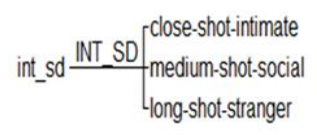

Fig. 2 Interpersonal function: Social distance

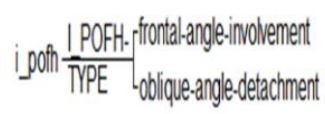

Fig. 4 Interpersonal function: Point of

view - horizontal axis

Besides qualitative analysis, the tool provides information regarding the frequency and distribution of the images' characteristics. For the polysemiotic analysis of website content, we added the verbal elements that relate to the image. That is, during annotation, we added the field "text" which anchors (Barthes 2007) to the annotated image.

In the following stages of the research further analysis of verbal content will be attempted through the compilation of a second type of corpora using the method of corpora compilation through the internet. Using the WebBootCAT tool, available in SketchEngine (Kilgarriff 2013; Kilgarriff and Grefenstettey 2003), which provides automatic annotation, we will attempt to create a corpus with university websites' verbal elements. This corpus will allow an in-depth study of the verbal realization of the discourse under study through the creation of concordances, statistical charts e.t.c. We are also planning to align the original and universalized versions of Greek university websites using SDL Trados Studio. For the analysis of verbal content we are planning to study the localization of the websites' communicative function (Reiss 1971/2002) and the verbal devices that realize it. The results from the polysemiotic corpus and the parallel verbal corpus are going to be associated with the sociocultural context on the basis of Hofstede's cultural dimensions (Hofstede 1991) and Hall's high- and low-context cultures (Hall 1976).

The methodology adopted, including both types of corpora is depicted in the following figure: 


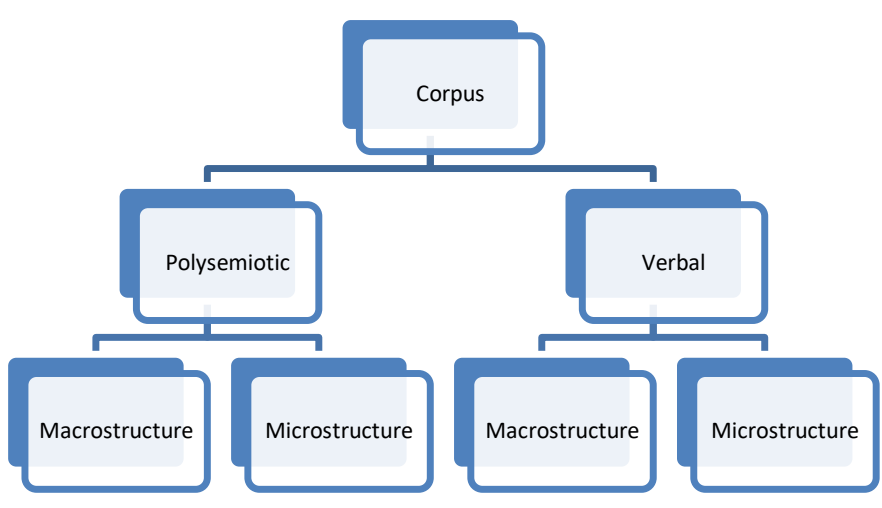

Fig. 5 Methodology for the interlingual study of university websites

The whole process includes two parallel corpora that include Greek and French websites (original and universalized versions) and a comparable monolingual corpus (Mc Enery and Wilson 1996; Peters et al. 1996).

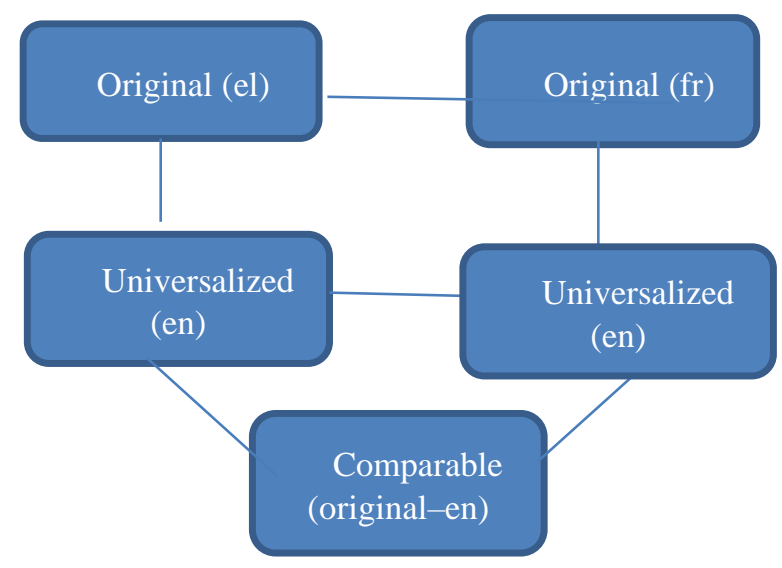

Fig. 6 The five university website versions under study and the comparison relations among them.

In this way, the statistical results regarding pictorial elements from the tool can be combined with the verbal information introduced and thus, enhance analysis of two semiotic systems in parallel. 


\section{$4 \quad$ Preliminary results}

The comparative analysis of Greek and English/American monolingual corpora, which focused on the study of the denotational and connotational polysiotic meaning of the two versions, has revealed differences in the isotopies used in each case. These differences have been related to different educational ideologies in the respective sociocultural contexts (Charalampidou 2018). The divergence on the isotopic level with reference to online university content depicts the way universities define themselves as well as the way they define their target audience.

The isotopies that prevail in British and American websites express the universities' attempt to project an image in line with the needs of the market. They emphasize on quality of research, teaching, facilities and working environment which is indicative of their effort to provide proof of excellence which will lead to a high score in external assessments. The isotopies selected by British and American universities are, in almost all of the cases, interconnected with the isotopy of value of giving reflecting the university's submission to market rules, similarly to Fairclough 's (1993) findings in university brochures. In literature, British and American universities are described as extremely competitive and commodified (Saunders 2010; Hill and Kumar 2009; Olssen and Peters 2005; Hill 2003; Torres and Schugurensky 2002) and this is projected through the isotopies found in their websites. Either in the beginning or at the end of the homepage there is a link through which the user can donate to the university. On the contrary, in Greek university websites a diverging communication strategy seems to be followed in line with a different educational tradition. The values projected are those of knowledge, continuity and longevity of education and knowledge and hellenicity. The university is self-projected as a place where knowledge and education are generously offered without expecting any rewards and thus, fits a more Humboltian model of education. The use of a different rhetoric in Greek universities is not a surprise since their main resources come from the government and they do not rely on users' donations or students' fees.

Additionally, the compilation of monolingual polysemiotic corpora of the original and universalized Greek and French university websites allowed the study of the translation strategies adopted in each locale and their association with cultural characteristics and marketing principles (Charalampidou and Grammenidis forthcoming). Adopting a translation-oriented approach to localization we defined the notion of translation strategy as an umbrella term that can include the concept of localization strategy in multimodal genres, such as university websites, and attempted to apply functional translation theories to university website localization. What we found was that, although Greek university websites aspire to reach a wider audience, they do not seem to take into consideration the undefined cultural background of the receivers or the expectations that such an audience might have. They address the mean international student retaining the verbopictorial discourse that they use to address Greek-speaking students. On the other hand, French university websites make an attempt to respond to the needs and expectations of an international audience by modifying operative landing content and in many cases recreating content that projects the values promoted by the Bologna Declaration (for more details see Charalampidou and Grammenidis forthcoming). 
The conclusions that have been drawn from the first stages of the research reveal that polysemiotic corpora allow the translation studies scholar to adopt an in-depth translation- and semiotics-oriented approach to localization taking into consideration cultural, ideological and marketing parameters. A corpus restricted to text only would limit the research to the observation and analysis of verbal persuasive means, leaving aside their interaction with pictorial elements. However, images very often constitute the basic or even the exclusive means of meaning coneveyance. The compilation of polysemiotic corpora can also be of great use in the context of translator training for the development of multimodal literacy to translation students as well as for their training in the translation of multimodal genres. Since the postdoctoral research is on-going the next step involves creating verbal parallel corpora in SketchEngine and extending the study with statistical results regarding operative verbal devices. In this way, more objective conclusions can be drawn with reference to divergence or convergence in operative discourse depending on cultural dimensions. The extension of the corpora to include a greater number of university websites is also required in order to reach safer conclusions.

\section{References}

1. Apperson, G.: How University Websites Portray Study Abroad. Elon Journal of Undergraduate Research in Communications 6 (2), (2015), http://www.elon.edu/docs/e-web/academics/communications/research/vol6no2/01_GinaApperson.pdf, last accessed 2016/12/15.

2. Askehave, I., Nielsen, E.A.: Web Mediated Genres - A Challenge to Traditional Genre Theory. In Working paper nr.6, Centre for Virksomhedskommunikation, Aarhus School of Business (2004).

3. Baldry, A., Thibault, P.J.: Multimodal Transcription and Text Analysis. Equinox, London (2006).

4. Bateman, J.: Multimodality and Genre. A Foundation for the Systematic Analysis of Multimodal Documents. Palgrave Macmillan, Basingstone and New York (2008).

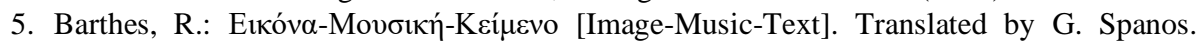
Plethron Publications, Athens (2007).

6. Bernardini, S., Ferraresi, A., Gaspari F.: Institutional academic English in the European contexts: a web-as-corpus approach to comparing native and non-native languages. In: López, A. L., Jiménez R.C. (eds.) English in the European context: The EHEA Challenge. Peter Lang, Bern, pp. 27-54 (2010).

7. Bohle, R. Publication Design for Editors. Prentice Hall, New Jersey (1990).

8. del Galdo, E.: Internationalisation and translation. Some guidelines for the design of humancomputer interfaces. In: Nielsen, J. (ed.) Designing User Interfaces for International Use, pp. 1-10. Elsevier, Amsterdam (1990).

9. Callahan, E.: Cultural Similarities and Differences in the Design of University Websites. Journal of Computer-Mediated Communication 11, 239-273 (2006).

10. Callahan, E. and Herring S. C.: Language Choice on University Websites: Longitudinal Trends. International Journal of Communication 6, 322-355 (2012).

11. Charalampidou, P.: In search of the myth in multicultural website design: the case of English university website versions in the British, the American and the Greek locale. In: Frangopoulos, M., Zantides, E. (eds). Design as Semiosis, Special Issue of PUNCTUM. International journal of Semiotics 4(1), 35-62 (2018). 
12. Charalampidou, P., Grammenidis. S.: Addressing the international student: translating French and Greek university websites into English. mTm 12, (forthcoming in 2021).

13. Fairclough, N.: Critical Discourse Analysis and the Marketization of Public Discourse: The Universities. Discourse and Society 4 (2), 133-168 (1993).

14. Floros, G., Charalampidou, P.: Website localization: Asymmetries and terminological challenges. The Journal of Internationalization and Localization 6(2), 108-130 (2020).

15. Dormann, C., Chisalita, C.: Cultural values in web site design. In ECCE-11: Eleventh European Conference on Cognitive Ergonomics, September 8-11, Catania, Italy (2002).

16. Flowerdew, J.: Concordancing as a tool in Course Design. System 21 (2), 231-244. Exeter (1993).

17. Fritz, G.: Coherence in Hypertext. In: Bublitz, W., Lenk, U., Ventola, E. (eds.) Coherence in Spoken and Written Discourse. How to Create it and How to Describe it, pp. 221-232. John Benjamins, Amsterdam (1999).

18. Gambier, Y.: Vers de nouvelles perspectives traductionnelles et traductologiques. In: Bulut, A., Uras-Yilmaz (eds) Proceedings of the International Colloquium of Translation: Translation in all its Aspects with Focus on International Dialogue. Istanbul, pp. 32-47 (2009).

19. Greimas A. J.: Structural Semantics: An Attempt at a Method, trans. Daniele McDowell, Ronald Schleifer and Alan Velie. University of Nebraska Press, Lincoln, Nebraska (1966/1983).

20. Habert, B.: Portrait de linguiste(s) à l'instrument. Texto, X/4 (2005).

21. Hall, E. T.: Beyond Culture. Anchor Press/Doubleday, Garden City, NY (1976).

22. Hermans, T.: Translation in Systems. Descriptive and System-oriented Approaches Explained. St. Jerome, Manchester (1999).

23. Hill, D.: Global neo-liberalism, the deformation of education and resistance. The Journal of Critical Education Policy Studies 1(1), 1-28 (2003).

24. Hill, D., Kumar, R.: Global neoliberalism and education and its consequences. Routledge Studies in Education and Neoliberalism 3. Routledge, London (2009).

25. Hofstede, G.: Cultures and Organisations: Software of the Mind. Mc Graw-Hill, New York (1991).

26. Holmes, J.S.: Translated! Papers on Literary Translation and Translation Studies. Rodopi, Amsterdam (1988).

27. Hunston, S.: Corpora in Applied Linguistics. Cambridge University Press, Cambridge (2002).

28. Jewitt, C.: The Routledge Handbook of Multimodal Anlaysis. Routledge, London (2009/2011).

29. Kilgarriff, A.: Terminology finding, parallel corpora and bilingual word sketches. In: The Sketch Engine ASLIB 35th Translating and the Computer conference, London (2013),

30. www.kilgarriff.co.uk/publications2.htm, last accessed 2018/10/8.

31. Kilgarriff, A., Grefenstettey, G.: Introduction to the special issue on the web as corpus. Computational Linguistics - Special issue on web as corpus 29 (3), 333-347 (2003).

32. Kress, G., Van Leeuwen, T.: Reading images: The grammar of visual design. Routledge, London (1996/2006).

33. Landow, G.P.: Hypertext 2.0: The Convergence of Contemporary Critical Theory and Technology. John Hopkins University Press, Baltimore (1997).

34. Leech, G.: Adding Linguistic Annotation. In: Wynne, M. (ed.) Developing Linguistic Corpora: a Guide to Good Practice, pp. 17-29. Oxbrow Books, Oxford (2005).

35. Lemke, J.: Multimedia Genres for Science Education and Scientific Literacy. In: Sclheppegrell, M., Colombi M. C. (eds.) Developing advanced Literacy in First and and Second Languages. Erlbaum, New York (2002). 
36. Leonardi, P.: Cultural variability in web interface design: Communicating US Hispanic cultural values on the Internet. In: Sudweeks, F., Ess, C. (eds.) Proceedings Cultural Attitudes Towards Communication and Technology 2002. Murdoch, Western Australia: School of Information Technology, Murdoch University, pp. 297-315 (2002).

37. Marcus, A., Gould, E.W.: Cultural Dimensions and Global Web User-Interface Design: What? So What? Now What? In: Proceedings of the 6th Conference on Human Factors and the Web (2000), http://www.amanda.com/resources/hfweb2000/hfweb00.marcus.html, last accessed 2019/3/1.

38. Martin, J.R.: Analysing genre: functional parameters. In Frances, C., Martin, J.R. (eds.) Genre and Institutions: Social Processes in the Workplace and School, pp. 3-39. Continuum, London and New York (1997).

39. McEnery, T., Wilson, A.: Corpus Linguistics. Edinburgh University Press, Edinburgh (1996).

40. Munday, J. (2001/2008) Introducing Translation Studies: Theories and Applications. London/New York: Routledge.

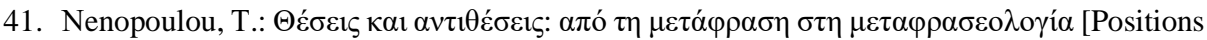

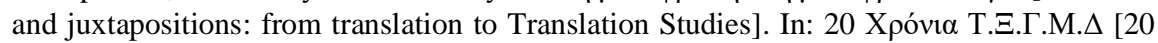
years Department of Foreign Languages, Translation and Interpreting], Anniversary volume. Diavlos, Athens (2007).

42. O' Donnell, M.: Demonstration of the UAM CorpusTool for text and image annotation. In: Proceedings of the ACL-08: HLT Demo Session (Companion Volume), pp. 13-16 (2008), https://www.uam.es/proyetosinv/woslac/DOCUMENTS/Presentations\%20and\%20articles/ ODonnellACL08.pdf, last accessed 2018/1/7.

43. O'Halloran, K.: Multimodal Discourse Analysis: Systemic functional perspectives. Continuum, London and New York (2004).

44. Olssen, M., Peters, M.: Neoliberalism, higher education and the knowledge economy: From the free market to knowledge capitalism. Journal of Educational Policy 20 (3), 313-345 (2005).

45. Reiss, K.: La critique des traductions, ses possibilités et ses limites.Translation Artois, C. B. Presses Université (1971/2002).

46. Peters, C., Picchi, E., Biagini, L.: Parallel and Comparable Bilingual Corpora in Language Teaching and Learning. In: Botley, S., Glass, J., McEnery, T., Wilson, A. (eds). Proceedings of Teaching and Language Corpora 1996. UCREL Technical Papers 9 (Special Issue), Lancaster University 1996, pp. 68-82 (1996).

47. Robbins, S. Stylianou, A.C.: A Study of Cultural Differences in Global Corporate Websites. Journal of Computer Information Systems 42, 3-9 (2002).

48. Russo, P., Boor, S.: How fluent is your interface? Designing for international users. In: Proceedings INTERCHI '93 Conference on Human Factors in Computing Systems: INTERACT '93 and CHI '93, pp. 342-347. ACM Press, Amsterdam (1993).

49. Salerno-O'Shea, P.: A Comparative Analysis of Website Expressions of National Culture and Mediation. In: CLCWeb: Comparative Literature and Culture 8.2 (2006), http://docs.lib.purdue.edu/clcweb/vol8/iss2/2/, last accessed 2018/2/2.

50. Santini, M.: Interpreting Genre Evolution on the Web. In: EACL 2006 Workshop: NEW TEXT - Wikis and blogs and other dynamic text sources. Preface to the Proceedings. ERCIM news (2006).

51. Saunders, D. B.: Neoliberal Ideology and Public Higher Education in the United States. Journal for Critical Education Policy Studies 8 (1), $41-77$ (2010).

52. Schmid-Isler, S.: The Language of Digital Genres: A Semiotic Investigation of Style and Iconology on the World Wide Web. In: Proceedings of the 33rd Hawaii International 
Conference on System Sciences (2006), http://csdl2.computer.org/comp/proceedings/hicss/2000/0493/03/04933012.pdf, last accessed 2018/3/7.

53. Sheppard, C., Scholtz, J.: The Effects of Cultural Markers on Web Site Use. In Proceedings of the 5th Conference on Human Factors \& the Web (1999), http://zing.ncsl.nist.gov/hfweb/proceedings/sheppard, last accessed 2018/3/7.

54. Simin, S., Tavangar, M., Pinna, A.: Marketing and Culture in University Websites. CLCWeb: Comparative Literature and Culture 13.4 (2011), http://dx.doi.org/10.7771/14814374.1703.

55. Snell-Hornby, M., Pöchhacker, F., Kaindl, K. (eds): Translation Studies. An Interdiscipline. John Benjamins, Amsterdam \& Philadelphia (1994).

56. Storrer, A.: Kohärenz in Text und Hypertext. In: Henning L. (ed.) Text im digitalen Medium. Linguistische Aspekte von Textdesign, Texttechnologie und Hypertext Engineering, pp. 3365. Westdeutscher Verlag, Opladen (1999).

57. Tognini-Bonelli, E.: Functionally complete units of meaning across English and Italian. In: Altenberg, B., Granger, S. (eds). Lexis in Contrast: Corpus-based Approaches, pp. 73-95. John Benjamins, Amsterdam 2002.

58. Tomášková, R.: A walk through the multimodal landscape of University Websites. In: Brno Studies in English 41(1) (2015),

59. http://www.phil.muni.cz/plonedata/wkaa/BSE/Articles\%20in\%20Press/BSE_2015-41(1)XX_Tomaskova_-_Article_in_Print.pdf, last accessed 2018/2/5.

60. Tomášková, R.: Advertising Education: Interpersonal Aspects in the Genre of University Websites. In: Hopkinson, C., Tomášková, R., Blažková, B. (eds.) Power and Persuasion: Interpersonal discourse strategies in the public domain, pp.44-73. University of Ostrava, Ostrava (2011).

61. Torres, C. A., Schugurensky, D.: The political economy of higher education in the era of neoliberal globalization: Latin America in comparative perspective. Higher Education 43(4), 429-455 (2002).

62. van Leeuwen, T.: Discourse and Practice. New Tools for Critical Discourse Analysis. Oxford University Press, Oxford (2008).

63. Ventola, E., Arsenio J. M. G.: The World Told and the World Shown. Multisemiotic Issues. Palgrave Macmillan, Basingstoke and New York (2009).

64. Wee, C.K.A.: A systemic-functional approach to multi-semiotic texts. (Unpublished Honours thesis). National University of Singapore (1999).

65. Yli-jokipii H.: The local and the global: an exploration into the Finnish and English Websites of a Finnish company. IEEE Transactions on Professional Communication 44 (2), 104-113, 2001.

66. Zanettin, F.: Parallel Words: Designing a Bilingual Database for Translation Activities. In: Wilson, A., McEnery, T. (eds) Corpora in Language Education and Research: a Selection of Papers from Talc 94.UCREL technical papers, 4, pp. 99-111. UCREL, Lancaster (1994). 